\title{
Canadian hospital architecture: how we got here
}

\author{
See also www.cmaj.ca/lookup/doi/10.1503/cmaj.150735
}

$\mathrm{T}$ oday's hospitals look a lot like hotels, shopping malls and even airports. They frequently feature multi-storey atria, lots of glass and a certain glitzy style. The entrance to SickKids in Toronto, for example, recalls the neighbouring Eaton Centre, designed by the same architects (Appendix 1). The Walter C. Mackenzie Health Sciences Centre in Edmonton and nearby West Edmonton Mall (Appendix 1) are cut from the same cloth. But hospitals of the 1950s and 1960s didn't resemble malls at all. They looked more like office buildings: Toronto's 1951 Hospital for Sick Children is a perfect example. And hospitals built before World War II, such as the Ottawa Civic Hospital and the Kingston General Hospital, had a strong civic presence, more akin to a school or a town hall. They looked public rather than private. What drives change in hospital architecture? Why and how has hospital design transformed?

Many architectural historians avoid hospitals, perhaps because of their complexity, and as a result, hospitals are glaringly absent from standard architectural history texts. The exceptions are the 15th-century Ospedale degli Innocenti by Filippo Brunelleschi and Alvar Aalto's sanatorium in Paimio, Finland, famously used as an example of "functionalism" by Sigfried Giedion in his blockbuster book, Space, Time and Architecture. ${ }^{1}$ A compelling question for those of us who dare to go there, however, is the relation of the building's changing form to medicine. Was the post-germ theory hospital different? Did antibiotics disinfect the hospital? What is functionalism today?

My position on these questions is that the histories of hospital architecture and medical practice have rarely converged. ${ }^{2-4}$ Hospitals are influenced by medicine, of course, in the same ways that schools are influenced by education, but also and perhaps more significantly by a myriad of other factors that have shaped many building types in the last century or so, including hospitals.

The four-part diagram shown in Figure 1 illustrates a simplified lineup of hospital types from the past 165 years. From roughly the Crimean War to World War I, hospitals looked like other reform institutions that featured big, open wards: workhouses, orphanages, convents, even prisons. This is the hospital of Florence Nightingale, where 30-some patients lay in parallel rows of narrow beds. Ventilation, ventilation and ventilation were the three main planning ideas driving the form of this largely philanthropic institution, often called the pavilion plan because the buildings were surrounded by fresh air. This hospital type was part institution and part residence, with nurses and other staff members living on site. Montréal's Royal Victoria Hospital of 1893 is an outstanding Canadian example.

Between the world wars, hospitals remained conservative and dignified institutional buildings when viewed from the street, but the plans differed drastically from the pavilion plan buildings that preceded them. Inside the Ottawa Civic Hospital of 1924, for example, instead of open wards, smaller rooms were clustered for efficiency. Physicians could expect to find all their admitted patients in smaller rooms along double-loaded corridors that resembled a hotel arrangement. Surgery was no longer performed in an amphitheatre but rather carried out in a suite of highly specialized rooms, each devoted to a specific function. Interwar hospitals looked like elegant hotels, taking cues from the tradition of aristocratic housing. They featured drop-off by automobile, elegant lobbies and fine food. These buildings convinced middleclass Canadians that they were better off in hospitals than at home when seriously ill. The architecture thus functioned as a tool of persuasion, rather than healing.

International style modernism appeared as the hospital-as-office-tower after World War II. We associate this efficiency with tonsillectomies, appen-

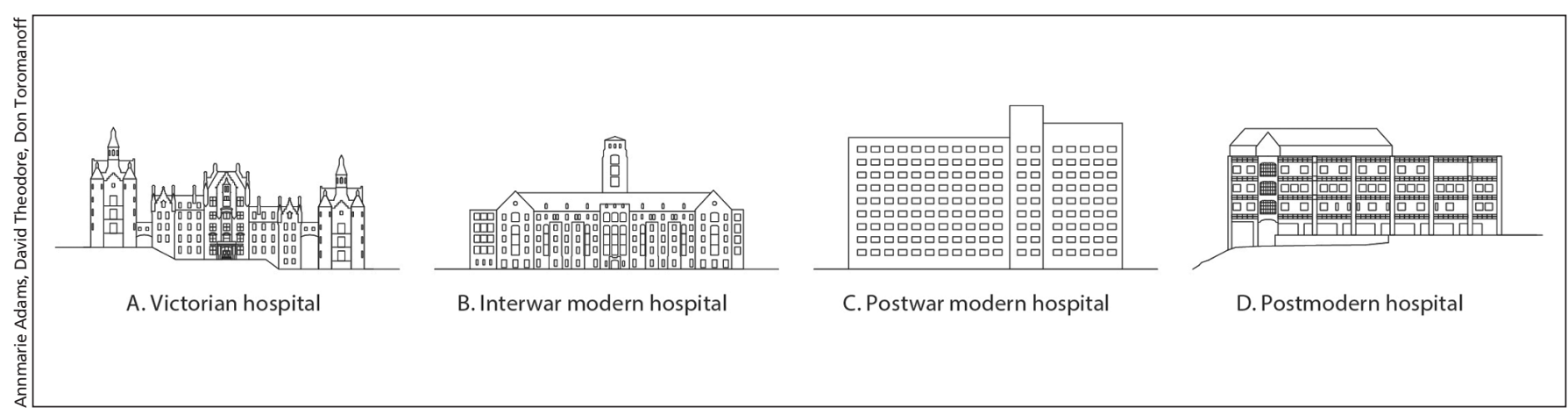

Figure 1: Diagram showing hospital evolution since the Victorian era. Montreal's Royal Victoria Hospital: a layered history. Montréal: unpublished heritage study for the Ville de Montréal; 2012. p. 8. 
dectomies, cesarean deliveries and routine cardiac surgery. Its architecture featured wide, sterile white corridors and centralized nursing stations that truly served as control centres; it's the hospital featured in popular soap operas like General Hospital, where we'd expect to encounter someone like Dr. Kildare waiting for the all-important elevator. a perfect fit with atrium-based architecture, normalizing a trip to the hospital by making it more like the mall. Example? Alberta Children's Hospital in Calgary.

Goodbye, Ben Casey; hello, Nurse Jackie. Welcome to your workplace, with its splendid glass roof, therapeutic garden, interfaith chapel, decentralized nursing stations, see-through high-speed

\section{Hospital architecture is shaped by at least three interrelated factors that don't touch many other building types.}

Residents of Montréal know this form well in the Montreal General Hospital (Appendix 1). We only know it's a hospital and not a downtown office tower because of the sign and the flashing lights of the ambulances parked outside. Vancouver General Hospital's Centennial Pavilion and the University Hospital in London, Ontario, are also good examples of this type.

Then, around 1980, hospitals we might call postmodern appeared. These were colourful, whimsical and downright consumerist. The tower lost its appeal and hospitals spread horizontally, becoming blocky and slick, rather than tall and sleek. Critics pointed to the neutral interiors of the postwar tower as evidence of soullessness, and technologies got hidden. Lobbies, especially, began to look like shopping malls, and other parts of the hospital seemed cozy and homelike. Bright colours on the exterior of hospitals made them read like billboards for fun and play, in a blatant attempt to distract and de-stress patients. Especially commissioned art found its way into hospital budgets and spaces with the same mandate to delight. Inspired by American hospitals, private rooms became an ideal, and we learned to behave more like customers than patients, dutifully taking numbers in waiting rooms and staying overnight with admitted family members on custom-made, multipurpose reclining furniture. Architects rediscovered the therapeutic affordances of nature and views, prompted by the rise of evidencebased research that measured the outcomes of design decisions. Patient- and family-centred care, with its focus on autonomy and whole-person health, was elevators and mango-coloured walls. Be sure to grab a nonfat, decaf, venti latte on your way in (whereas the postwar tower had been decidedly Maxwell House). The new McGill University Health Centre in Montréal, for example, takes its planning cues from big-box stores, industrial parks and suburbia (Appendix 1). The website on the just-opened facility boasts the now-expected social, rather than medical features: a Zen garden, airport-style drop-offs and an interior street.

Admittedly, hospitals are obviously different from other building types in important ways. Hospital architecture is shaped by at least three interrelated factors that don't touch many other building types. Because of their complexity, hospitals are designed by specialized firms (like airports). This means few architects get a chance to design a hospital, which restricts innovation. Second, innovation

\section{Further reading} Caduceus 1993;9:119-30. University Press; 2003. 1984:224:420-1. is complicated by strict regulations and controls (like long-term care). Third, hospitals need to look up to date to attract and retain excellent staff (perhaps more than any other building type).

It's a strange moment in Canadian hospital architecture. We haven't produced a world-class hospital since the late 1970s, with the design of the evercontroversial McMaster University Health Sciences Centre. Our hospital standards today are largely shaped by American models, even though our health care systems differ. New American hospitals, for example, need insured patients to remain full and competitive. Canadian hospitals, owing to universal health care insurance, do not suffer for lack of patients. Our 11 architecture schools are only beginning to teach basic health care design; and our medical students don't learn about architecture.

\section{Annmarie Adams PhD}

School of Architecture, McGill University, Montréal, Que.

\section{References}

1. Giedion S. Space, time and architecture: the growth of a new tradition. Cambridge (MA): Harvard University Press; 1949.

2. Risse GB. Mending bodies, saving souls: a history of hospitals. New York: Oxford University Press; 1999.

3. Rosenberg CE. The care of strangers: the rise of America's hospital system. New York: Basic; 1987.

4. Stevens R. In sickness and in wealth: American hospitals in the twentieth century. New York: Basic; 1989.

Appendix 1 is available at www.cmaj.ca/lookup/ suppl/doi:10.1503/cmaj.151233/-/DC1

CMAJ 2016. DOI:10.1503/cmaj.151233

- Adams A. Medicine by design: the architect and the modern hospital, 1893-1943. Minneapolis: University of Minnesota Press; 2008.

- Connor JT. Bigger than a bread box: medical buildings as museum artifacts.

- Forty A. The modern hospital in England and France: the social and medical uses of architecture. In: King AD, editor. Buildings and society: essays on the social development of the built environment. London (UK): Routledge \& Kegan Paul; 1980:61-93.

- Sloane DC, Beverlie CS. Medicine moves to the mall. Baltimore: Johns Hopkins

- Sternberg EM. Healing spaces: the science of place and well-being. Cambridge (MA): Belknap Press of Harvard University Press; 2009.

- Thompson JD, Goldin G. The hospital: a social and architectural history. New Haven (CT): Yale University Press; 1975.

- Ulrich RS. View through a window may influence recovery from surgery. Science

- Verderber S, Fine DJ. Healthcare architecture in an era of radical transformation. New Haven (CT): Yale University Press; 2000. 